\title{
SUGESTÕES PARA PADRONIZAÇÃO DA METODOLOGIA EMPREGADA EM ESTUDOS PALINOLÓGICOS DO QUATERNÁRIO
}

\author{
Jean-Pierre YBERT \\ Maria Léa SALGADO-LABOURIAU \\ Ortrud Monika BARTH \\ Maria Luísa LORSCHEITTER \\ Márcia Aguiar de BARROS \\ Sérgio Augusto de Miranda CHAVES \\ Cynthia Fernandes Pinto da LUZ \\ Maira RIBEIRO \\ Rita SCHEEL \\ Kátia Ferraz VICENTINI
}

\begin{abstract}
A metodologia detalhada a seguir foi definida pelos autores durante reuniões organizadas em Belo Horizonte por ocasião do 3 ? Congresso da Associação Brasileira de Estudos do Quaternário (ABEQUA) em 1991. Consiste na padronização dos métodos de coleta e dos tratamentos físico-químicos a serem aplicados na preparação das amostras destinadas a estudos em Palinologia. É recomendada para estudos palinológicos relacionados com o Quaternário e deverá ser utilizada sempre que for possível, com a finalidade de permitir uma comparação entre os trabalhos dos diversos autores e a utilização dos dados publicados pela comunidade científica.

Caso as condições de conservação ou a natureza do material não permitirem o uso desta metodologia, o autor deverá descrever detalhadamente o seu procedimento.
\end{abstract}

\section{AMOSTRAGEM}

\subsection{Sedimentos de superfície}

Os estudos palinológicos de sedimentos quaternários têm como principal finalidade avaliar os climas do passado através da reconstituição da cobertura vegetal e de sua evolução no tempo.

Um dos alvos importantes recomendados pelo PIGB (Programa Internacional Geosfera Biosfera) é a avaliação das biomassas vegetais em cada época. Para chegar a essa avaliação é indispensável conhecer as relações existentes entre o conjunto esporopolínico depositado em um determinado local e o(s) tipo(s) de vegetação encontrado(s) no mesmo ou em seus arredores, tanto qualitativa como quantitativamente. Isso deverá ser feito a partir da coleta de amostras de sedimentos de superfície, debaixo da cobertura vegetal, em todos os tipos de associações ocorrentes na área em estudo.
As pesquisas serão realizadas preferencialmente em locais onde a vegetação foi nada ou pouco perturbada pela ação do homem e para os quais existam dados meteorológicos e fitossociológicos. Esses últimos podem ser levantados no momento das coletas palinológicas.

Os sedimentos quaternários são geralmente obtidos por meio de testemunhos retirados de turfeiras, lagoas, lagos ou veredas, ou seja, em ambientes atualmente abertos. Será, portanto, necessário analisar também os sedimentos de superfície dessas formações, a fim de poder avaliar a representatividade dos espectros polínicos em relação à vegetação local e/ou regional; também, no caso dos lagos, essas análises servirão para avaliar as variações dos níveis lacustres.

A amostragem dos sedimentos de superfície será efetuada da seguinte forma:

\subsubsection{Estudos não-relacionados com levantamen-} tos fitossociológicos

As amostras serão retiradas nos dois centímetros superiores do solo, debaixo da serrapilheira (quando esta existir), ao longo de transects estabelecidos em função do local de estudo e incluindo os diversos tipos de vegetação da região.

No caso de vegetação aberta (savanas, campos rupestres etc.) as amostras serão coletadas de preferência em locais onde exista uma preservação melhor do pólen, por exemplo pequenas depressões, nas quais a água tende a acumular-se.

1.1.2 Estudos relacionados com levantamentos fitossociológicos

Vinte amostras, repartidas de maneira aleatória em cada parcela do levantamento fitosso- 
ciológico, serão retiradas nos dois centímetros superiores do solo debaixo da serrapilheira (quando esta existir). Essas amostras serão misturadas, constituindo uma única, que representará o tipo de vegetação em questão.

$\mathrm{O}$ procedimento será o mesmo em vegetações abertas, procurando-se os locais mais favoráveis para a conservação do pólen.

\subsubsection{Amostras de sedimentos lacustres}

As amostras lacustres poderão ser coletadas com um testemunhador do tipo "Mondsee", ao longo de transects, de uma margem a outra do lago. Um desses deverá ser orientado paralelamente à direção dos ventos dominantes, de tal modo que se possa levar em conta o transporte do pólen flutuante na superfície e que tende a se acumular na beira do lago oposta à direção do vento. $\mathrm{O}$ número de amostras será definido em função da extensão do lago. As amostras serão tomadas fora das embocaduras e desembocaduras de rios e, quando for o caso, na proximidade dos pontos de testemunhagem de sedimentos quaternários. Serão retiradas no primeiro ou nos dois centímetros superiores do sedimento lacustre.

\subsection{Sedimentos quaternários}

Em todos os casos, perfis ou testemunhos, devem-se reservar amostras para outros fins, tais como análises sedimentológicas, isotópicas, geoquímicas e de outros microfósseis (ostracódios, diatomáceas etc.).

As amostras destinadas a análises isotópicas de carbono serão secadas o mais rápido possível depois de serem separadas, para evitar o desenvolvimento de fungos. A temperatura de secagem não deverá ultrapassar $40^{\circ} \mathrm{C}$.

As amostras de superfície ou de testemunhos destinadas à análise palinológica serão guardadas úmidas em câmara fria, dentro de sacos plásticos hermeticamente fechados. Algumas gotas de solução de fenol a $1 \%$ podem ser adicionadas à amostra para evitar a contaminação por fungos modernos.

A distância vertical entre as amostras de perfis ou de testemunhos, destinadas a análises palinológicas, será no máximo de dez centímetros, procurando-se manter constante esse intervalo. Essa distância poderá ser reduzida em casos especiais de mudanças litológicas ou do conjunto ("'assemblage') palinológico. Cada amostra terá de preferência uma espessura (profundidade estratigráfica) de um centímetro, mas poderá ser ampliada para dois centímetros quando o sedimento for muito pobre em palinomorfos.
Havendo um número suficiente de datações, antes de iniciar os estudos palinológicos, a malha de amostragem será estabelecida de tal maneira que seja mantido um intervalo de tempo constante (VINCENS, 1992).

A superfície, o volume e o peso de cada amostra serão medidos para o cálculo dos fluxos polínicos (concentração, input e influxo).

\section{PREPARAÇÃO DAS AMOSTRAS}

Todas as amostras de superfície e quaternárias serão tratadas pela mesma metodologia para evitar distorções entre os espectros polínicos e permitir a comparação dos dados atuais e fósseis, bem como dos resultados de diferentes autores.

A preparação das amostras será feita de modo a poder avaliar a freqüência relativa e absoluta dos palinomorfos, seja por mensurações de volumes (COUR, 1974) ou por introdução de esporos ou pólen exótico (STOCKMARR, 1971; SALGADO-LABOURIAU \& RULL, 1986). Deve-se procurar usar sempre o mesmo volume ou peso úmido de sedimento em um perfil.

\subsection{Roteiro para tratamento químico:}

- Introdução do pólen exótico;

- $\mathrm{HCl}$ a $10 \%$ se o sedimento for carbonatado e se forem utilizadas pílulas de Lycopodium;

- Lavagem com água destilada;

- $\mathrm{KOH}$ a $10 \%$ em fervura durante $5 \mathrm{~min}$;

- Peneiramento com malha de 200 a $250 \mu \mathrm{m}$ e guarda do resíduo para o estudo de macrorrestos vegetais;

- Lavagem com água destilada;

- Ácido acético concentrado (duas vezes);

- Acetólise em fervura durante $4 \mathrm{~min}$;

- Lavagem com água destilada;

- HF a $40 \%$ durante uma noite. Pode-se substituir ou complementar o uso do HF pela separação por densidade com cloreto de zinco ou bromofórmio $(\mathrm{D}=2)$ se a amostra estiver muito pobre em palinomorfos ou se permanecerem muitos resíduos minerais;

- Lavagem com água destilada;

- $\mathrm{HCl}$ a $10 \%$ em fervura durante $15 \mathrm{~min}$. Repetir a operação até o líquido ficar limpo;

- Lavagem com água destilada;

- Montagem das lâminas.

Observação: toda lavagem e eliminação de substâncias químicas será feita através de centrifugação.

\section{CONTAGEM}

Será sempre efetuada em um mínimo de três lâminas. 
A contagem dos palinomorfos será efetuada até chegar à saturação. A curva de saturação, que define a relação entre o número de grãos contados e o número de novos taxa encontrados, será estabelecida para cada amostra em função dos elementos que entram no cálculo da soma polínica. Caso um tipo de pólen apresente uma percentagem muito elevada, será eliminado da soma para a construção da curva.

\section{APRESENTAÇÃO DOS DIAGRAMAS}

\subsection{Freqüência absoluta}

As freqüências absolutas serão calculadas em relação à unidade de volume de sedimento ou, na sua falta, em relação à unidade de peso seco.

Cada diagrama apresentará, à esquerda, a coluna litológica juntamente com os resultados das datações por $\mathrm{C} 14 \mathrm{e}$, a seguir, a curva de cada palinomorfo.

\subsection{Freqüência relativa}

As percentagens serão calculadas sobre a soma polínica.
A soma polínica constará de todos os grãos de pólen ou somente dos elementos regionais que permitirão chegar às interpretações climáticas, quando for possível diferenciá-los. Os elementos locais indicadores de ambientes úmidos serão considerados à parte e definidos por cada pesquisador em função do conhecimento que ele tem de sua área de trabalho e da possibilidade de determinar com exatidão esses taxa. A percentagem de cada um dos elementos locais será calculada em função da soma polínica.

Para permitir a comparação entre os diagramas de diversos autores, o número total de grãos de pólen, componentes da soma polínica, será indicado para cada nível analisado, em uma coluna colocada à direita do diagrama.

$O$ diagrama apresentará também a coluna litológica à esquerda, junto com os resultados de datações por C14.

Além desses diagramas de freqüências absolutas e relativas, os autores poderão apresentar outros diagramas percentuais, baseados em características especiais, para atender a diversas interpretações, tais como a avaliação da batimetria dos lagos, a evolução de uma turfeira etc.

\section{REFERÊNCIAS BIBLIOGRÁFICAS}

COUR, P. 1974. Nouvelles techniques de détection des flux et des retombées polliniques: étude de la sédimentation des pollens et des spores à la surface du sol. Pollen et Spores, 16: 103-142.

SALGADO-LABOURIAU, M.L. \& RULL, V. 1986. A method of introducing exotic pol- len for palaeoecological analysis of sediments. Rev. Pal. Pal., 47: 97-103.

STOCKMARR, J. 1971. Tablets with spores used in absolute pollen analysis. Pollen et Spores, 13(14): 615-621.

VINCENS, A. 1992. Compte rendu de la réunion ECOFIT du 23 Janvier 1992. (Inédito).

\section{Endereço dos autores:}

- Jean-Pierre Ybert, Ortrud Monika Barth, Márcia Aguiar de Barros, Sérgio Augusto de Miranda Chaves, Cynthia Fernandes Pinto da Luz, Rita Scheel - Laboratório de Palinologia, Departamento de Botânica, IB, CCS, UFRJ, 21.949-900, Illha do Fundão - Rio de Janeiro, Brasil.

- Maria Léa Salgado-Labouriau, Maira Ribeiro e Kátia Ferraz Vicentini - Laboratório de Geologia Geral, Instituto de Geociências, 70.910, UnB, Brasília, Brasil.

- Maria Luísa Lorscheitter - Departamento de Botânica, UFRGS, 90.040, Porto Alegre - RS, Brasil. 